\title{
Global surgery for pediatric hydrocephalus in the developing world: a review of the history, challenges, and future directions
}

\author{
Ryan T. Muir, BHSc, ${ }^{1}$ Shelly Wang, MD, MPH, ${ }^{2,3}$ and Benjamin C. Warf, MD ${ }^{4,5}$ \\ ${ }^{1}$ Faculty of Medicine, and 'Division of Neurosurgery, Department of Surgery, University of Toronto, Ontario, Canada; ${ }^{3}$ Department \\ of Biostatistics and Epidemiology, Harvard T.H. Chan School of Public Health; ${ }^{4}$ Department of Neurosurgery, Boston Children's \\ Hospital, and Department of Global Health and Social Medicine, Harvard Medical School, Boston, Massachusetts; and ${ }^{5} \mathrm{CURE}$ \\ Children's Hospital of Uganda, Mbale, Uganda
}

OBJECTIVE Pediatric hydrocephalus is one of the most common neurosurgical conditions and is a major contributor to the global burden of surgically treatable diseases. Significant health disparities exist for the treatment of hydrocephalus in developing nations due to a combination of medical, environmental, and socioeconomic factors. This review aims to provide the international neurosurgery community with an overview of the current challenges and future directions of neurosurgical care for children with hydrocephalus in low-income countries.

METHODS The authors conducted a literature review around the topic of pediatric hydrocephalus in the context of global surgery, the unique challenges to creating access to care in low-income countries, and current international efforts to address the problem.

RESULTS Developing countries face the greatest burden of pediatric hydrocephalus due to high birth rates and greater risk of neonatal infections. This burden is related to more general global health challenges, including malnutrition, infectious diseases, maternal and perinatal risk factors, and education gaps. Unique challenges pertaining to the treatment of hydrocephalus in the developing world include a preponderance of postinfectious hydrocephalus, limited resources, and restricted access to neurosurgical care. In the 21st century, several organizations have established programs that provide hydrocephalus treatment and neurosurgical training in Africa, Central and South America, Haiti, and Southeast Asia. These international efforts have employed various models to achieve the goals of providing safe, sustainable, and cost-effective treatment.

CONCLUSIONS Broader commitment from the pediatric neurosurgery community, increased funding, public education, surgeon training, and ongoing surgical innovation will be needed to meaningfully address the global burden of untreated hydrocephalus.

http://thejns.org/doi/abs/10.3171/2016.7.FOCUS16273

KEY WORDS pediatrics; hydrocephalus; cerebrospinal fluid; neuroendoscopy; global health; developing countries

$\mathrm{H}$ YDROCEPHALUS is the most common neurosurgical condition in children. ${ }^{30}$ In developed countries, the incidence of congenital hydrocephalus is $0.5-1 / 1000$ live births, while neonatal acquired hydrocephalus is $3-5 / 1000$ live births ${ }^{14,39,55,77}$ Although no reliable incidence estimate exists for hydrocephalus in most developing countries, it is likely higher due to nutritional deficiencies, low infant birth weight, greater incidence of perinatal and neonatal infections, and delayed antenatal diagnosis..$^{40,51}$ In addition to a higher disease incidence, developing countries also face a greater burden of care for hydrocephalus, likely attributed to a combination of medical and socioeconomic factors, including higher birth rates, poverty, cultural notions of health, poor infrastructure, unstable politics, and limited access to neurosurgical treatment. ${ }^{10,51,67}$

ABBREVIATIONS CPC = choroid plexus cauterization; DALY = disability-adjusted life-year; $E T V=$ endoscopic third ventriculostomy; VP = ventriculoperitoneal . 
Thus, children with hydrocephalus in low- and middleincome countries face significant and unique barriers to treatment. ${ }^{6,62,68,76}$ The past decade has witnessed increased awareness of the burden of hydrocephalus in developing countries, greater understanding of its etiology and characteristics, and the initiation of programs by a number of groups and organizations to increase access to treatment for these children. This narrative literature review attempts to summarize what is known, highlight what is being done, and encourage broader engagement from the pediatric neurosurgery community.

\section{Methods}

A literature search was performed using MEDLINE and Embase from database inception to the present, using terms pertaining to global surgery, developing countries and pediatric hydrocephalus, limited to English-language literature. This search strategy yielded 137 articles from MEDLINE and 241 articles from Embase, which were reviewed.

\section{Global Burden of Disease}

Global surgery for pediatric hydrocephalus is faced with a great burden of disease resulting from scarce resources, cultural and geographic barriers to treatment, differences in etiology, and inadequate neurosurgical manpower.

\section{Increased Health Demand in Minimally Resourced Settings}

Compared with children admitted to other hospital services, those with hydrocephalus require a disproportionately greater share of health resources for acute and longitudinal management. ${ }^{50}$ Children with ventriculoperitoneal (VP) shunts, for instance, often undergo multiple admissions and surgeries over the course of their shuntdependent life. In under-resourced settings where timely revision is often compromised by the cost to low- to middle-income families and great distances to neurosurgical centers, shunt failure may be associated with greater mortality than in high-income countries. ${ }^{24,44,54,59}$

Limited access to neurosurgical care also worsens the burden of disease in developing countries. In Africa, there is an unequal distribution of neurosurgical resources across the continent, with $86 \%$ of practicing neurosurgeons located in South Africa and North Africa. ${ }^{22}$ In subSaharan Africa, there is approximately 1 neurosurgeon per 5 million people and in East Africa 1 neurosurgeon per 10 million people,, 20 compared with 1 neurosurgeon per 100,000 people in European countries..$^{22}$ Furthermore, in sub-Saharan Africa, it is estimated that more than 100,000 newborns annually develop hydrocephalus before 1 year of age. ${ }^{46}$ In Nigeria, hydrocephalus accounts for $32 \%$ of congenital neurosurgical conditions; ${ }^{4}$ in Kenya, hydrocephalus represents the highest surgical burden of disease in male children $;^{78}$ and in Uganda, hydrocephalus accounts for $59 \%$ of neurosurgical conditions ${ }^{67}$ With more than half of Africa's population younger than 18 years, it is remarkable that fewer than $10 \%$ of neurosurgeons have subspecialty training in pediatric neurosurgery. ${ }^{5}$ In Haiti, with a population of 10 million, one-third of whom are younger than 14 years of age living in poverty, access to neurosurgical care is also sparse. ${ }^{76}$ In many impoverished countries of Central and South America, CSF-diverting procedures account for nearly $40 \%$ of total neurosurgical procedures. ${ }^{37}$

This high burden of disease is coupled with the reality that most families do not have ready access to specialized neurosurgical care, and many cultural and economic factors lead to delayed presentation to medical care, often weeks to months after the symptomatic onset of hydrocephalus. $^{27,29}$ Some factors include shame for carrying a sick child, unawareness of treatment, poverty, initial attempt with traditional healing methods, poor understanding of early signs and symptoms, social taboos, or lack of physical access to health care ${ }^{34,37,53,57}$ Limited access to already limited health resources, greater burden of pediatric hydrocephalus, and complex social and geographical barriers pose significant challenges for international global surgery efforts.

\section{Hydrocephalus Etiology}

The pathogenesis of pediatric hydrocephalus is multifaceted, ${ }^{30}$ and emerging evidence suggests that different etiologies exist in developing versus developed nations. ${ }^{49,64}$ While pediatric hydrocephalus in developed countries commonly arises from intraventricular hemorrhage of prematurity and congenital causes, in developing countries postinfectious hydrocephalus predominates, likely due to the greater incidence of neonatal sepsis. A combination of inadequate maternal-fetal care and unsanitary living environments contribute to more prevalent and severe cases of neonatal sepsis leading to postinfectious hydrocephalus, which accounts for $60 \%$ of hydrocephalus cases in Uganda $^{64}$ and $40 \%$ of cases in South Africa. ${ }^{25}$ Postinfectious hydrocephalus, however, is not the leading etiology reported from all developing countries, with hydrocephalus secondary to neural tube defects being especially common, along with aqueductal stenosis and hemorrhage, in Kenya, Nigeria, Cameroon, Zambia, Zimbabwe, Malawi, and Saudi Arabia. ${ }^{2,3,19,23,28,63,65}$

The spectrum of bacteria causing neonatal sepsis and postinfectious hydrocephalus also differs between developing and developed countries. ${ }^{32,36}$ In developed countries, Group B Streptococcus, Escherichia coli, and Listeria monocytogenes most commonly cause neonatal sepsis. In the developing world, gram-negative organisms, but rarely Group B Streptococcus, predominate. ${ }^{32,36}$ Furthermore, differences in bacterial speciation may depend on the season: cases of postinfectious hydrocephalus had a greater prevalence of Acinetobacter species in the ventricular CSF of Ugandan infants during the rainy season..$^{36}$ Another study in Uganda found that the peak incidence of postinfectious hydrocephalus was related to climate, with infection-onset peaks in the intermediate period between rainy and dry seasons. ${ }^{49}$

Bacteriological studies to date raise concerns as to whether current antimicrobial protocols in developing nations include adequate coverage of gram-negative bacteria. Recent evidence supports this concern, as most of the gram-negative bacilli isolated from VP shunt infec- 
tions in Kenya were resistant to cefazolin, ciprofloxacin, and gentamycin. ${ }^{43}$ These findings invite future efforts in global surgery to assess the adequacy of current antibiotic regimens in neonatal sepsis, with the hope of adequately treating and preventing cases that may otherwise progress to postinfectious hydrocephalus.

\section{Surgical Management}

VP shunt insertion is the mainstay of hydrocephalus treatment in the developing world..$^{18,23}$ This treatment is effective, but is not without complications of shunt extrusion, breakage, overdrainage, obstruction, or infection and the potential for many revisions over a lifetime. ${ }^{18}$ There is an especially high upfront burden of disease, with nearly half of all shunts failing in the first 2 years. ${ }^{18}$ In developing countries, risk factors for poor outcomes after VP shunt treatment include younger age, comorbidities like anemia and malnutrition, advanced presentation, and the absence of adequate diagnostic imaging. ${ }^{23}$ Worldwide complication rates of VP shunts are reported to be between $1 \%$ and $40 \%$, but developing countries face the greatest burden. ${ }^{23,31}$

While the incidence of VP shunt infections ranges from $2 \%$ to $9 \%$ in developed countries ${ }^{15}$ in developing countries it reportedly occurs in $8.6 \%-50 \% .8,12,23,26,31,33,41$, 42,56 The microbiology of shunt infection also differs. In developed countries, Staphylococcus aureus and Staphylococcus epidermidis species predominate, while isolates from developing countries are mostly gram-negative organisms. ${ }^{7,21,35,43}$ However, not all studies report this pattern. While Escherichia coli, Acinetobacter, Klebsiella, Pseudomonas, Salmonella typhimurium, and Proteus are isolated in greater proportions of shunt infections compared with the developed world, S. aureus and coagulase-negative staphylococci were still common isolates in Malaysia, Kenya, and Nigeria. ${ }^{1,42,56}$

The preponderance of gram-negative and enteric bacteria in shunt infections may be related to poor hygiene, malnutrition, and the hospital environments in developing countries. Hospital-acquired sources include operating rooms without sterile drapes or operating tables, suites shared with general surgery, ${ }^{21}$ overcrowding, and poor isolation of those with gram-negative infections..$^{43}$ Overall, these data suggest that not only should public health measures improve surgical sterility, hygiene, and more efficacious isolation of those with known infection, but they must also ensure adequate antibiotic coverage for both gram-negative and gram-positive bacteria. Most gramnegative isolates in these settings are multidrug resistanta factor that also contributes to the greater morbidity and mortality of shunt infections in the developing world. ${ }^{43}$

Endoscopic third ventriculostomy (ETV) offers freedom from hardware-related complications, and it seems especially appropriate in limited resource settings, where it offers a morbidity-reducing and cost-effective solution..$^{17,69}$ The addition of choroid plexus cauterization (CPC), with the goal of decreasing CSF production and changing CSF dynamics, was refined over the past decade through pioneering work in sub-Saharan Africa. ${ }^{52,61,71,72,75}$ The success of ETV/CPC across all hydrocephalus etiologies ranges from $66 \%$ to $81.9 \% 9,60,61,63,70,71,74,75$ and has been shown to be more efficacious than stand-alone ETV in children younger than 2 years. Limitations to ETV/CPC in global surgery include the absence of preoperative high-quality $\mathrm{MRI}^{72}$ and a limited number of neurosurgeons skilled in endoscopic techniques. ${ }^{21}$

\section{Economic Considerations}

With the advent of the Millennium Development Goals, there has been a great emphasis on improving maternal health and reducing child mortality, malnutrition, and communicable diseases. Surgically managed conditions are commonly not perceived as cost-effective, while costeffective health measures, such as vaccination, often take precedence in global health campaigns. ${ }^{13}$

Although the economic burden of hydrocephalus management is great, emerging evidence suggests that the neurosurgical management of hydrocephalus is costeffective in the developing world. In a Ugandan study, the cost-effectiveness ratio for hydrocephalus surgery was \$108.74 US dollars per disability-adjusted life-year (DALY)-comparable to WHO vaccination campaigns (\$51.86-\$220.39 per DALY). ${ }^{13}$ Furthermore, although the up-front cost of treating all incident cases of hydrocephalus in sub-Saharan Africa in 1 year would approach $\$ 190$ million, it would confer an estimated lifetime economic benefit of $\$ 1.4$ billion. ${ }^{69}$ Similar results have been demonstrated in cost-effectiveness analyses in Haiti $^{76}$ and Guatemala. ${ }^{16}$ Furthermore, ETV averted nearly twice as many DALYs compared with VP shunting. ${ }^{16}$ However, in centers unable to offer ETV or in patients with ETV failure, VP shunting continues to be the mainstay treatment, and successful use of cheaper shunt systems has minimized VP shunting cost without compromising outcome. ${ }^{59}$ Other important considerations when evaluating the economic impact of hydrocephalus are the costs to the family, which include the costs of travel, opportunity, and investigations. ${ }^{16}$ In a Nigerian study, $41 \%$ of patients presenting with suspected hydrocephalus could not afford transcranial ultrasound or CT. ${ }^{2}$

Overall, this work suggests that current neurosurgical interventions for hydrocephalus are cost-effective and that there is room for innovation to make surgery more affordable for families and health systems, without compromising safety.

\section{Current International Efforts}

A number of international efforts have helped provide global neurosurgical care and facilitate sustainable neurosurgical training. ${ }^{62}$ Various organizations, including the Foundation for International Education in Neurological Surgery, the World Federation of Neurosurgical Societies, and the International Society for Pediatric Neurosurgery have contributed greatly to the development of global neurosurgical care, creation of medical infrastructure, and advancement of neurosurgical education. The extent of international efforts for neurosurgery is expanding and promising. International programs specifically providing treatment or neurosurgical education in the field of pediatric hydrocephalus are considered in this review and are highlighted in Table 1. These efforts span across Africa, Haiti, and Central and South America. 


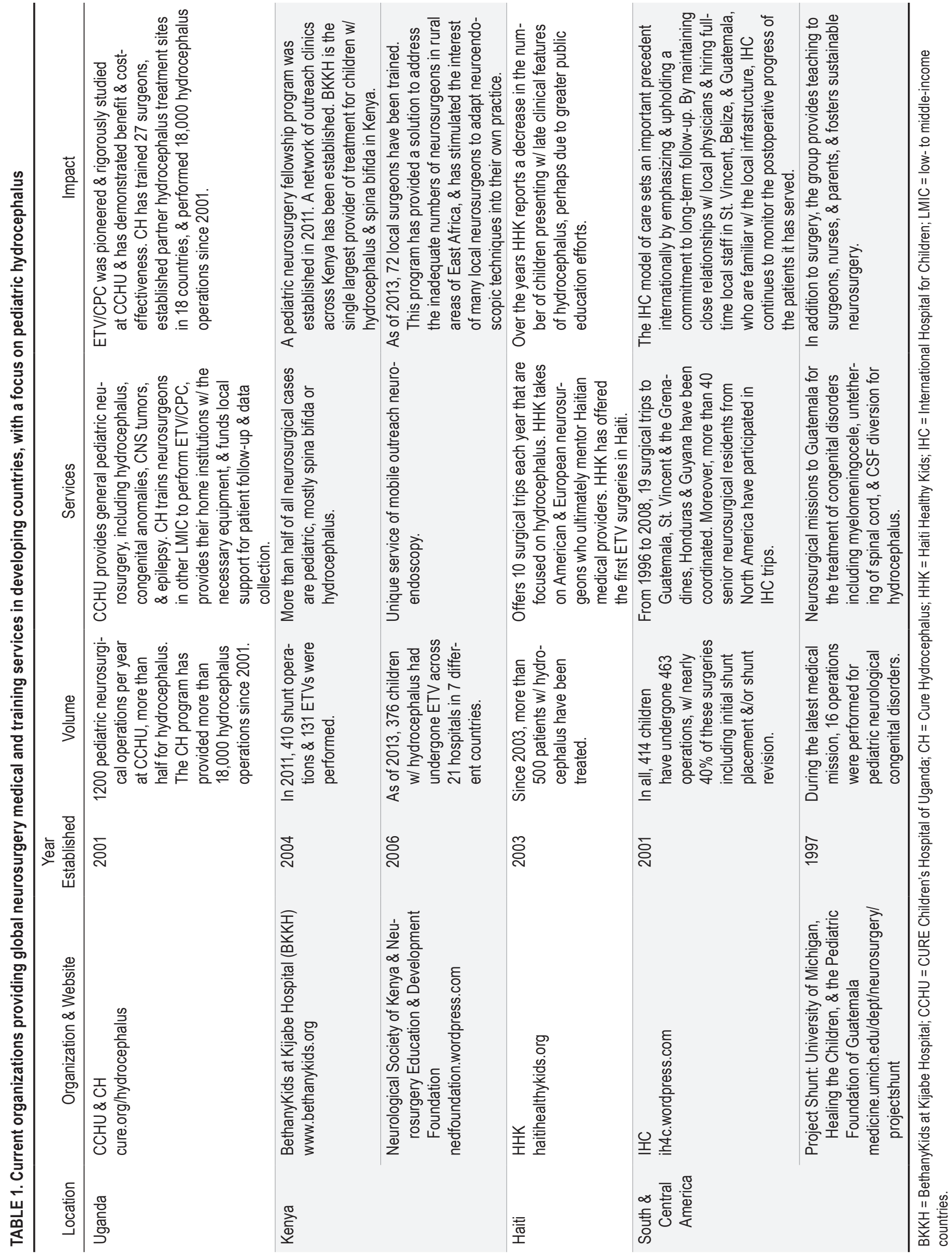




\section{Major Challenges}

\section{Limitations in Health Care Infrastructure}

Providing neurosurgery in a developing country is a fine balance between operating under suboptimal conditions and upholding an obligation to nonmaleficence. Managing hydrocephalus peri- and postoperatively is challenged by limits in neurosurgical manpower, supportive consultations, ICU capabilities, imaging technology, operative tools, and medications..$^{20,38,47,58,76}$

Government remuneration models also contribute unique challenges to conducting pediatric neurosurgery in the developing world. In Kenya for instance, the government's health care budget is $\$ 15 /$ year per person, resulting in a large discrepancy between the capacity to treat and the ability to afford treatment. ${ }^{47}$ With many families making a daily income of $\$ 2$, it makes affording a CT scan (\$75) impossible for most. ${ }^{47}$ The provision of care at the Kijabe Hospital in Kenya is further complicated by the government's remuneration of $\$ 29$ per day for hospital operating costs. ${ }^{47}$ Similarly, in Guatemala, a mere \$256 per capita is spent on health care, whereas the United States spends $\$ 6096$ per capita. ${ }^{37}$ Therefore, the majority of hydrocephalus care is financially supported by funding agencies and donations of surgical materials by manufacturers in developed nations and the surgeon's personal expense. ${ }^{37,76}$

\section{Challenges in Neurosurgical Training}

Training of local physicians and other health care providers is a necessary catalyst to generate future pediatric neurosurgeons. There is an immense need for pediatric neurosurgeons in the developing world, but also a significant gap in the capacity to train them. Many countries do not have neurosurgery residency programs, and in some places where residency programs do exist, additional challenges like inadequate operative resources, funding, research opportunities, and career mentorship are prevailing issues. ${ }^{38}$ In contrast to residents in North America who learn primarily by operating with the attending physician, residents in Africa rely heavily on textbooks and observation. ${ }^{5}$ Even after graduating, trainees are strongly encouraged to obtain training in Europe or North America. ${ }^{5}$ The scarcity of neurosurgeon teachers, limited residency programs, and high attrition of residents and neurosurgeons to other countries with greater resources, makes training a difficult feat in developing countries. ${ }^{68}$ However, some residency training programs have endeavored to train neurosurgeons for countries in sub-Saharan Africa, including those at University of Cape Town, Mohamed V University in Morocco, and through the College of Surgeons of East, Central, and Southern Africa. ${ }^{22,62}$ Other residency programs in under-resourced countries have residents rotate through more rural areas such as the program at the University of Nairobi where residents complete 1-3 months of pediatric neurosurgical training in rural Kijabe..$^{5,38}$ Nonetheless, until adequate infrastructure, residency training programs, and initiatives to retain local neurosurgeons are in place, the training of local general surgeons has been proposed. ${ }^{62,76} \mathrm{Of}$ course such an endeavor, if adopted, would have to be selective in teaching reasonably acquirable skills relevant to common neurosurgical cases in areas without current neurosurgical care. ${ }^{68}$

\section{Ethics of International Aid}

Unique challenges exist for international surgical aid in developing countries. Criticisms exist for medical missions that periodically provide care, as they can promote increased dependency on foreign aid and the disenfranchisement of local health care providers. ${ }^{16,58,76}$ Another important issue is that of surgical follow-up, ${ }^{76}$ as many surgical missions perform needed surgery, but continuity of care is compromised when a medical team leaves a country. Many of the international surgical initiatives for hydrocephalus to date have attempted to address the aforementioned issues by improving the longevity and continuity of local initiatives, providing training for local health professionals and fellowship programs for the next generation of local neurosurgeons, following up with patients, and crafting innovative interventions, such as ETV/CPC, that are ultimately more suitable to a developing nation's scarce resources..$^{10,11,45,48,62,66,68}$

\section{Future Directions}

Our review of the literature underscores that pediatric hydrocephalus is an important and inadequately addressed component of the global burden of disease. Existing approaches to this problem provide templates for future refinement and expansion of programs that seek to increase access to optimal treatment for children everywhere. In addition, there needs to be a fundamental reframing of the current global perspective that regards pediatric neurosurgery as being too specialized of a service for developing nations. Many have appropriately advocated for investments in primary care and disease prevention; however, we find evidence suggesting that the burden of pediatric hydrocephalus in many developing nations is sufficiently significant to warrant greater attention. Training and equipping neurosurgeons to establish an increasing number of sustainable centers for hydrocephalus treatment will be an ongoing and important challenge. In addition, the burden of pediatric hydrocephalus is intimately connected to more general public health concerns, such as malnutrition, communicable diseases, maternal risk factors, and education. As such, we suggest that future efforts, in addition to increasing access to neurosurgical treatment, should also focus on preventable causes of hydrocephalus including neonatal sepsis, neural tube defects, and infant prematurity. This may include education and policy promoting sanitary birthing practices, identification of the key pathogens responsible for postinfectious hydrocephalus (which may vary by region and season), modification of antibiotic regimens for neonatal infections, and continued research on the potential environmental sources of infection. Another crucial element to decrease the morbidity and mortality associated with delayed presentation is public education. We need to create community-based initiatives that provide information about hydrocephalus, as well as education initiatives for primary health care providers and health policy advisors and authorities. Organizations already engaged in such international educa- 
tion and advocacy work include the International Federation for Spina Bifida and Hydrocephalus (www.ifglobal. org) and the PUSH! Global Alliance (www.pu-sh.org).

\section{Conclusions}

We have provided an overview of pediatric hydrocephalus in the context of global health. We have reviewed the health and economic burdens of hydrocephalus, revealed evidence that suggests regional variations in etiology, highlighted innovative surgical approaches and current international efforts to increase access to treatment, and suggested future directions, including the need to reduce the global burden of disease through prevention. It is a daunting task that begs the engagement of many partners.

\section{References}

1. Abdullah J, Naing NN: Hydrocephalic children presenting to a Malaysian community-based university hospital over an 8-year period. Pediatr Neurosurg 34:13-19, 2001

2. Adeleye AO, Olowookere KG: Central nervous system congenital anomalies: a prospective neurosurgical observational study from Nigeria. Congenit Anom (Kyoto) 49:258-261, 2009

3. Adeloye A: Management of infantile hydrocephalus in Central Africa. Trop Doct 31:67-70, 2001

4. Afolabi A, Shokunbi M: Socio-economic implications of the surgical treatment of hydrocephalus. Niger J Paediatr 20:94-97, 1993

5. Albright AL, Ferson SS: Developing pediatric neurosurgery in a developing country. J Child Neurol 27:1559-1564, 2012

6. Aschoff A, Kremer P, Hashemi B, Kunze S: The scientific history of hydrocephalus and its treatment. Neurosurg Rev 22:67-95, 1999

7. Bokhary MA, Kamal H: Ventriculo-peritoneal shunt infections in infants and children. Libyan J Med 3:20-22, 2008

8. Bakhsh A: CSF shunt complications in infants-an experience from Pakistan. Pediatr Neurosurg 47:93-98, 2011

9. Bankole OB, Ojo OA, Nnadi MN, Kanu OOOJ, Olatosi JO: Early outcome of combined endoscopic third ventriculostomy and choroid plexus cauterization in childhood hydrocephalus. J Neurosurg Pediatr 15:524-528, 2015

10. Boivin MJ, Kakooza AM, Warf BC, Davidson LL, Grigorenko EL: Reducing neurodevelopmental disorders and disability through research and interventions. Nature 527:S155S160, 2015

11. Burton A: Infant hydrocephalus in Africa: spreading some good news. Lancet Neurol 14:789-790, 2015

12. Casey AT, Kimmings EJ, Kleinlugtebeld AD, Taylor WA, Harkness WF, Hayward RD: The long-term outlook for hydrocephalus in childhood. A ten-year cohort study of 155 patients. Pediatr Neurosurg 27:63-70, 1997

13. Chao TE, Sharma K, Mandigo M, Hagander L, Resch SC, Weiser TG, et al: Cost-effectiveness of surgery and its policy implications for global health: a systematic review and analysis. Lancet Glob Health 2: $334-\mathrm{e} 345,2014$

14. Chi JH, Fullerton HJ, Gupta N: Time trends and demographics of deaths from congenital hydrocephalus in children in the United States: National Center for Health Statistics data, 1979 to 1998. J Neurosurg 103 (2 Suppl):113-118, 2005

15. Crnich CJ, Safdar N, Maki DG: Infections associated with implanted medical devices, in Finch RG, Greenwood D, Norrby SR, Whitley RJ (ed): Antiobiotics and Chemotherapy: Anti-Infective Agents and Their Uses in Therapy, ed 8. New York: Churchill Livingston, 2003, pp 575-618

16. Davis MC, Than KD, Garton HJ: Cost effectiveness of a short-term pediatric neurosurgical brigade to Guatemala. World Neurosurg 82:974-979, 2014
17. Di Rocco C, Massimi L, Tamburrini G: Shunts vs endoscopic third ventriculostomy in infants: are there different types and/or rates of complications? A review. Childs Nerv Syst 22:1573-1589, 2006

18. Drake JM, Kestle JRW, Milner R, Cinalli G, Boop F, Piatt J $\mathrm{Jr}$, et al: Randomized trial of cerebrospinal fluid shunt valve design in pediatric hydrocephalus. Neurosurgery 43:294305, 1998

19. el Awad ME: Infantile hydrocephalus in the south-western region of Saudi Arabia. Ann Trop Paediatr 12:335-338, 1992

20. El Khamlichi A: African neurosurgery: current situation, priorities, and needs. Neurosurgery 48:1344-1347, 2001

21. Emejulu JKC, Ugwu JO: Combating complications following ventriculoperitoneal shunting in a new centre. Pediatr Neurosurg 45:446-450, 2009

22. Fuller A, Tran T, Muhumuza M, Haglund MM: Building neurosurgical capacity in low and middle income countries. eNeurologicalSci 3:1-6, 2016

23. Gathura E, Poenaru D, Bransford R, Albright AL: Outcomes of ventriculoperitoneal shunt insertion in Sub-Saharan Africa. J Neurosurg Pediatr 6:329-335, 2010

24. Ghritlaharey RK, Budhwani KS, Shrivastava DK, Srivastava $\mathrm{J}$ : Ventriculoperitoneal shunt complications needing shunt revision in children: a review of 5 years of experience with 48 revisions. Afr J Paediatr Surg 9:32-39, 2012

25. Handler LC, Wright MG: Postmeningitic hydrocephalus in infancy. Ventriculography with special reference to ventricular septa. Neuroradiology 16:31-35, 1978

26. Heij HA: The fate of ventriculo-peritonea1 shunts and outcome of revision surgery. East Cent African J Surg 5:17-19, 1998

27. Idowu O, Doherty A, Tiamiyu O: Initial experience with endoscopic third ventriculostomy in Nigeria, West Africa. Childs Nerv Syst 24:253-255, 257, 2008

28. Idowu O, Olumide A: Etiology and cranial CT scan profile of nontumoral hydrocephalus in a tertiary black African hospital. J Neurosurg Pediatr 7:397-400, 2011

29. Idowu OE, Falope LO, Idowu AT: Outcome of endoscopic third ventriculostomy and Chhabra shunt system in noncommunicating non-tumor childhood hydrocephalus. J Pediatr Neurosci 4:66-69, 2009

30. Kahle KT, Kulkarni AV, Limbrick DD Jr, Warf BC: Hydrocephalus in children. Lancet 387:788-799, 2016

31. Kinasha ADA, Kahamba JF, Semali IT: Complications of ventriculoperitoneal shunts in children in Dar es Salaam. East Cent African J Surg 10:55-59, 2005

32. Kiwanuka J, Bazira J, Mwanga J, Tumusiime D, Nyesigire E, Lwanga N, et al: The microbial spectrum of neonatal sepsis in Uganda: recovery of culturable bacteria in mother-infant pairs. PLoS One 8:e72775, 2013

33. Komolafe EO, Adeolu AA, Komolafe MA: Treatment of cerebrospinal fluid shunting complications in a Nigerian neurosurgery programme. Case illustrations and review. Pediatr Neurosurg 44:36-42, 2008

34. Komolafe EO, Komolafe MA, Adeolu AA: Factors implicated for late presentations of gross congenital anomaly of the nervous system in a developing nation. Br $\mathbf{J}$ Neurosurg 22:764-768, 2008

35. Lane JD, Mugamba J, Ssenyonga P, Warf BC: Effectiveness of the Bactiseal Universal Shunt for reducing shunt infection in a sub-Saharan African context: a retrospective cohort study in 160 Ugandan children. J Neurosurg Pediatr 13:140-144, 2014

36. Li L, Padhi A, Ranjeva SL, Donaldson SC, Warf BC, Mugamba J, et al: Association of bacteria with hydrocephalus in Ugandan infants. J Neurosurg Pediatr 7:73-87, 2011

37. Mainthia R, Tye GW, Shapiro J, Doppenberg EMR, Ward JD: A model for neurosurgical humanitarian aid based on 12 
years of medical trips to South and Central America. J Neurosurg Pediatr 4:4-9, 2009

38. Mansouri A, Okechi H, Albright AL, Bernstein M: Reconnaissance mission to the neurosurgical department in Kijabe Hospital, Kenya: a call for the submission of ideas and strategies. World Neurosurg 81:e14-e16, 2014

39. Munch TN, Rostgaard K, Rasmussen MLH, Wohlfahrt J, Juhler M, Melbye M: Familial aggregation of congenital hydrocephalus in a nationwide cohort. Brain 135:2409-2415, 2012

40. Murshid WR, Jarallah JS, Dad MI: Epidemiology of infantile hydrocephalus in Saudi Arabia: birth prevalence and associated factors. Pediatr Neurosurg 32:119-123, 2000

41. Mwachaka PM, Obonyo NG, Mutiso BK, Ranketi S, Mwang'ombe N: Ventriculoperitoneal shunt complications: a three-year retrospective study in a Kenyan national teaching and referral hospital. Pediatr Neurosurg 46:1-5, 2010

42. Mwang'ombe NJM, Omulo T: Ventriculoperitoneal shunt surgery and shunt infections in children with non-tumour hydrocephalus at the Kenyatta National Hospital, Nairobi. East Afr Med J 77:386-390, 2000

43. Ochieng' N, Okechi H, Ferson S, Albright AL: Bacteria causing ventriculoperitoneal shunt infections in a Kenyan population. J Neurosurg Pediatr 15:150-155, 2015

44. Paulsen AH, Lundar T, Lindegaard KF: Twenty-year outcome in young adults with childhood hydrocephalus: assessment of surgical outcome, work participation, and health-related quality of life. J Neurosurg Pediatr 6:527-535, 2010

45. Piquer J, Qureshi MM, Young PH: Impact of mobile endoscopy on neurosurgical development in East Africa. World Neurosurg 73:280-284, 2010

46. Piquer J, Qureshi MM, Young PH, Dempsey RJ: Neurosurgery education and development program to treat hydrocephalus and to develop neurosurgery in Africa using mobile neuroendoscopic training. J Neurosurg Pediatr 15:552-559, 2015

47. Qureshi MM, Oluoch-Olunya D: History of neurosurgery in Kenya, East Africa. World Neurosurg 73:261-263, 2010

48. Qureshi MM, Piquer J, Young PH: Mobile endoscopy: a treatment and training model for childhood hydrocephalus. World Neurosurg 79:S24.e1-S24.e4, 2013

49. Schiff SJ, Ranjeva SL, Sauer TD, Warf BC: Rainfall drives hydrocephalus in East Africa. J Neurosurg Pediatr 10:161167,2012

50. Simon TD, Riva-Cambrin J, Srivastava R, Bratton SL, Dean JM, Kestle JRW: Hospital care for children with hydrocephalus in the United States: utilization, charges, comorbidities, and deaths. J Neurosurg Pediatr 1:131-137, 2008

51. Stagno V, Navarrete EA, Mirone G, Esposito F: Management of hydrocephalus around the world. World Neurosurg 79 (2 Suppl):S23.e17-S23.e20, 2013

52. Stone SSD, Warf BC: Combined endoscopic third ventriculostomy and choroid plexus cauterization as primary treatment for infant hydrocephalus: a prospective North American series. J Neurosurg Pediatr 14:439-446, 2014

53. Tambo FFM, Djientcheu V, Chiabi A, Mbarnjuk SA, Walburga YJ, Mbonda E, et al: Our experience in the management of infantile hydrocephalus: a study on thirty-five regrouped cases in Yaounde, Cameroon. Afr J Paediatr Surg 8:199_ 202, 2011

54. Tuli S, Tuli J, Drake J, Spears J: Predictors of death in pediatric patients requiring cerebrospinal fluid shunts. J Neurosurg 100 (5 Suppl Pediatrics):442-446, 2004

55. Tully HM, Dobyns WB: Infantile hydrocephalus: a review of epidemiology, classification and causes. Eur J Med Genet 57:359-368, 2014

56. Uche EO, Onyia E, Mezue UC, Okorie E, Ozor II, Chikani MC: Determinants and outcomes of ventriculoperitoneal shunt infections in Enugu, Nigeria. Pediatr Neurosurg 49:75-80, 2013
57. van't Veer T, Meester H, Poenaru D, Kogei A, Augenstein K, Bransford R: Quality of life for families with spina bifida in Kenya. Trop Doct 38:160-162, 2008

58. Vargas J, Mayegga E, Nuwas E, Ellegala DB, Kucia EJ, Nicholas J: Brain surgery in the bush: adapting techniques and technology to fit the developing world. World Neurosurg 80:e91-e94, 2013

59. Warf BC: Comparison of 1-year outcomes for the Chhabra and Codman-Hakim Micro Precision shunt systems in Uganda: a prospective study in 195 children. J Neurosurg 102 (4 Suppl):358-362, 2005

60. Warf BC: Comparison of endoscopic third ventriculostomy alone and combined with choroid plexus cauterization in infants younger than 1 year of age: a prospective study in 550 African children. J Neurosurg 103 (6 Suppl):475-481, 2005

61. Warf BC: Congenital idiopathic hydrocephalus of infancy: the results of treatment by endoscopic third ventriculostomy with or without choroid plexus cauterization and suggestions for how it works. Childs Nerv Syst 29:935-940, 2013

62. Warf BC: Educate one to save a few. Educate a few to save many. World Neurosurg 79 (2 Suppl):S15.e15-S15.e18, 2013

63. Warf BC: Hydrocephalus associated with neural tube defects: characteristics, management, and outcome in sub-Saharan Africa. Childs Nerv Syst 27:1589-1594, 2011

64. Warf BC: Hydrocephalus in Uganda: the predominance of infectious origin and primary management with endoscopic third ventriculostomy. J Neurosurg 102 (1 Suppl): 1-15, 2005

65. Warf BC: Hydrocephalus treatment and outcome in African infants with myelomeningocele: what we have learned so far. Cerebrospinal Fluid Res 7 (Suppl 1):S3, 2010 (Abstract)

66. Warf BC: Neurosurgical humanitarian aid. J Neurosurg Pediatr 4:1-3, 2009

67. Warf BC: Pediatric hydrocephalus in East Africa: prevalence, causes, treatments, and strategies for the future. World Neurosurg 73:296-300, 2010

68. Warf BC: "Who is my neighbor?" Global neurosurgery in a non-zero-sum world. World Neurosurg 84:1547-1549, 2015

69. Warf BC, Alkire BC, Bhai S, Hughes C, Schiff SJ, Vincent JR, et al: Costs and benefits of neurosurgical intervention for infant hydrocephalus in sub-Saharan Africa. J Neurosurg Pediatr 8:509-521, 2011

70. Warf BC, Campbell JW: Combined endoscopic third ventriculostomy and choroid plexus cauterization as primary treatment of hydrocephalus for infants with myelomeningocele: long-term results of a prospective intent-to-treat study in 115 East African infants. J Neurosurg Pediatr 2:310-316, 2008

71. Warf BC, Dagi AR, Kaaya BN, Schiff SJ: Five-year survival and outcome of treatment for postinfectious hydrocephalus in Ugandan infants. J Neurosurg Pediatr 8:502-508, 2011

72. Warf BC, Dewan M, Mugamba J: Management of DandyWalker complex-associated infant hydrocephalus by combined endoscopic third ventriculostomy and choroid plexus cauterization. J Neurosurg Pediatr 8:377-383, 2011

73. Warf BC, Mugamba J, Kulkarni AV: Endoscopic third ventriculostomy in the treatment of childhood hydrocephalus in Uganda: report of a scoring system that predicts success. J Neurosurg Pediatr 5:143-148, 2010

74. Warf BC, Stagno V, Mugamba J: Encephalocele in Uganda: ethnic distinctions in lesion location, endoscopic management of hydrocephalus, and survival in 110 consecutive children. J Neurosurg Pediatr 7:88-93, 2011

75. Warf BC, Tracy S, Mugamba J: Long-term outcome for endoscopic third ventriculostomy alone or in combination with choroid plexus cauterization for congenital aqueductal stenosis in African infants. J Neurosurg Pediatr 10:108-111, 2012

76. Weil AG, Fallah A, Bhatia S, Ragheb J: Pediatric neurosur- 
gery in the developing world: the Haiti experience. J Craniofac Surg 26:1061-1065, 2015

77. Wiswell TE, Tuttle DJ, Northam RS, Simonds GR: Major congenital neurologic malformations. A 17-year survey. Am J Dis Child 144:61-67, 1990

78. Wu VK, Poenaru D, Poley MJ: Burden of surgical congenital anomalies in Kenya: a population-based study. J Trop Pediatr 59:195-202, 2013

\section{Disclosures}

The authors report no conflict of interest concerning the materials or methods used in this study or the findings specified in this paper.

\section{Author Contributions}

Conception and design: all authors. Acquisition of data: all authors. Analysis and interpretation of data: all authors. Drafting the article: all authors. Critically revising the article: all authors. Reviewed submitted version of manuscript: all authors. Approved the final version of the manuscript on behalf of all authors: Warf. Administrative/technical/material support: Warf. Study supervision: Warf.

\section{Correspondence}

Benjamin C. Warf, Department of Neurosurgery, Harvard Medical School, Boston Children's Hospital, 300 Longwood Ave., Boston, MA 02115. email: benjamin.warf@childrens.harvard.edu. 